OPEN ACCESS

Edited by:

Yiqiu Tan,

Harbin Institute of Technology, China

Reviewed by:

Qiang Yuan,

Central South University, China

Changjun Zhou,

Dalian University of Technology, China

*Correspondence:

Jinyan Feng

fjy@buaa.edu.cn

Specialty section:

This article was submitted to

Structural Materials,

a section of the journal

Frontiers in Materials

Received: 14 March 2020

Accepted: 09 June 2020

Published: 11 August 2020

Citation:

Liu X, An Y, Feng J, Zhu X and Li F (2020) Preparation and Properties

of Carbon Nanofiber Modified

Emulsified Asphalt Based on

Ultrasonication and Surfactant

and the Impact of $\mathrm{SBR}$ and $\mathrm{NH}_{4} \mathrm{Cl}$.

Front. Mater. 7:209.

doi: $10.3389 /$ fmats.2020.00209

\section{Preparation and Properties of Carbon Nanofiber Modified Emulsified Asphalt Based on Ultrasonication and Surfactant and the Impact of SBR and $\mathrm{NH}_{4} \mathrm{Cl}$}

\author{
Xuhang Liu ${ }^{1}$, Yuning An ${ }^{1}$, Jinyan Feng ${ }^{1 *}$, Xingyi Zhu ${ }^{2}$ and Feng $\mathrm{Li}^{1}$ \\ ${ }^{1}$ School of Transportation Science and Engineering, Beihang University, Beijing, China, ${ }^{2}$ College of Transportation \\ Engineering, Tongji University, Shanghai, China
}

Carbon nanofiber (CNF) is a nanomaterial with unique mechanical properties, which can improve the properties of composite materials effectively. Research focusses on the impact of CNF on asphalt, asphalt binders, and mixtures. Traditional emulsified asphalt presents a limited performance at both high and low temperatures. Emulsified asphalt with a better performance, is therefore required in engineering. Referring to research on CNF-asphalt, CNF is considered to improve the performance of emulsified asphalt. In this study, a preparation method for CNF modified emulsified asphalt with styrene-butadiene rubber (SBR) was proposed. Ultrasonication and surfactant were utilized to disperse the CNFs in water. The optimum dispersion surfactant percentages and ultrasonic energy density to disperse CNFs were determined through ultravioletvisible spectra (UV-vis spectra). The modified emulsified asphalt was produced using CNFs suspension with SBR as a modifier, and the properties of the residue, with different percentages of CNFs, were tested. Gel permeation chromatography (GPC) was performed to analyze the molecular size distribution. The results indicated that CNFs significantly improved high-temperature performance of the residue but decreased lowtemperature properties. The addition of SBR not only perfected storage stability but also improved low-temperature performance by introducing more small molecules.

Keywords: carbon nanofiber, dispersion, SBR, residue properties, GPC

\section{INTRODUCTION}

In the past few years, nanomaterials, especially carbon nanotube (CNT) and carbon nanofiber $(\mathrm{CNF})$, have presented advantages in composite materials and has attracted extensive investigation. There are many studies on the application of CNT/CNF in civil engineering because of their extraordinary properties (Pacheco-Torgal and Jalali, 2011). For example, carbon nanofibers exhibit excellent mechanical properties with Young's modulus from 25 to $200 \mathrm{GPa}$ (Lawrence et al., 2008) and tensile strength of up to $12 \mathrm{GPa}$ (Mordkovich, 2003).

For CNF reinforced composite materials, it is vital to obtain a uniform dispersion of CNFs in the matrix material to take advantage of the excellent mechanical properties of CNFs. Compared to $\mathrm{CNF}$, there are more studies on the dispersion of CNT that indicate the effectiveness of surfactant 
and ultrasonication to disperse CNTs in water uniformly (O’Connell et al., 2002; Strano et al., 2003). Considering a similar surface structure between CNT and CNF, the dispersion principle and method for these two materials should therefore also be similar.

There are many studies that focus on CNF reinforced cement. A. Yazdanbakhsh and Zoi S. Metaxa provided a method to produce carbon nanofiber modified cement with surfactant and ultrasonication (Yazdanbakhsh et al., 2009, 2010; Metaxa et al., 2013): first, CNFs were dispersed through ultrasonication in water containing surfactant, then the suspension was added to cement instead of water, and participated in hydration. Konsta-Gdoutos MS and Shah et al. researched CNF-cement composites further. They found significant improvements in flexural strength, Young's modulus, flexural toughness, and fracture toughness (Gdoutos et al., 2016). Zhu et al. (2018) researched the effect of the interfacial transition zone on Young's modulus of CNF reinforced cement concrete. Moreover, there is also research that indicates that the addition of CNFs significantly influences resistance to corrosion, electrical conductivity, and resistivity sensibility to structural damage of the nanocomposites (Galao et al., 2014; Konsta-Gdoutos and Aza, 2014; Konsta-Gdoutos et al., 2017).

The success of CNFs-cement composites has motivated studies on CNFs modified asphalt. According to the production of CNFs-cement materials, to prepare a CNF-asphalt composite material, the CNFs can be dispersed in the solvent and then be added to the asphalt. Khattak et al. (2013a) dispersed CNFs in kerosene or acetone by ultrasonication and then added the mixture into the asphalt. Kerosene or acetone eventually evaporated by heating (Khattak et al., 2013a,b). Asphalt mixtures with nanofibers also exhibit excellent mechanical properties like enhanced stiffness, higher dynamic modulus (Khattak et al., 2013a), and higher resistance to cracking under repeated loads (Khattak et al., 2013b). Furthermore, Khattak et al. (2013a) also studied the impact of CNFs modified asphalt on asphalt binder rheology through dynamic shear rheometer (DSR). They found that visco-elastic response and fatigue life were improved, which indicated higher resistance to rutting and fatigue (Khattak et al., 2012). Goh's research demonstrated that CNFs improved moisture susceptibility performance (decrease the moisture damage potential) of the mixture in most cases, and hot-mix asphalt mixture exhibited the greatest tensile strength with 0.75 wt $\%$ nanofibers (Goh et al., 2011). Despite these achievements, there are still issues. Generally, CNFs are easy to disperse in water with the assistance of surfactant and ultrasonication (get suspension), hence, there is a relatively uniform dispersion of nanofibers in cement, of which the suspension is a composition. By contrast, it is more difficult to disperse CNFs in asphalt directly, since the ultrasonication fails to work in high viscosity and hot liquid. Although agents like kerosene facilitate dispersion, they must ultimately be removed. Additionally, incomplete removal can affect performance.

Compared to the hot asphalt, considering that emulsified asphalt consists of asphalt and water, it is possible to produce emulsified asphalt with evenly dispersed CNFs by obtaining suspension first. Moreover, emulsified asphalt and relevant materials such as cold recycled mixture and cement asphalt emulsion mortar are environmentally friendly, however, their poor properties limit further development (Ouyang et al., 2018, 2020). It is therefore necessary to improve the performance of cold recycled mixture and cement asphalt emulsion mortar, of which improving the properties of emulsified asphalt is essential.

This paper proposed a method to prepare CNF modified emulsified asphalt. According to present research, CNFs only enhance high temperature performance, so in this study, SBR was used as a modifier. Furthermore, the properties of the evaporation residue of the emulsified asphalt were investigated. Gel permeation chromatography (GPC) was performed to analyze the effect of SBR on the molecular size distribution and low-temperature properties.

\section{PREPARATION OF CNFs MODIFIED EMULSIFIED ASPHALT}

\section{Materials}

One 70\# asphalt is selected as the base asphalt (Table 1). Carbon nanofibers are black powder (Figure 1) provided by Nanjing XFNANO Materials Tech Co., Ltd. All the CNFs are as-grown vapor grown carbon nanofibers (VGCNFs) produced at a high temperature with stable properties. The characteristic properties of CNFs are shown in Table 2. The surfactant is a kind of paleyellow transparent liquid with a density of $0.98 \mathrm{~g} / \mathrm{ml}$ provided by BASF Chemicals Co., Ltd (ID: GS8325).

\section{TABLE 1 | Properties of asphalt.}

\begin{tabular}{lc}
\hline Index & Result \\
\hline Penetration $(0.1 \mathrm{~mm})$ & 67 \\
Softening Point $\left({ }^{\circ} \mathrm{C}\right)$ & 47.5 \\
Ductility $\left(10^{\circ} \mathrm{C}\right)(\mathrm{cm})$ & 25 \\
Rotational viscosity $\left(135^{\circ} \mathrm{C}\right)(\mathrm{Pa} \cdot \mathrm{s})$ & 0.48 \\
$\mathrm{PI}(-)$ & -0.7
\end{tabular}

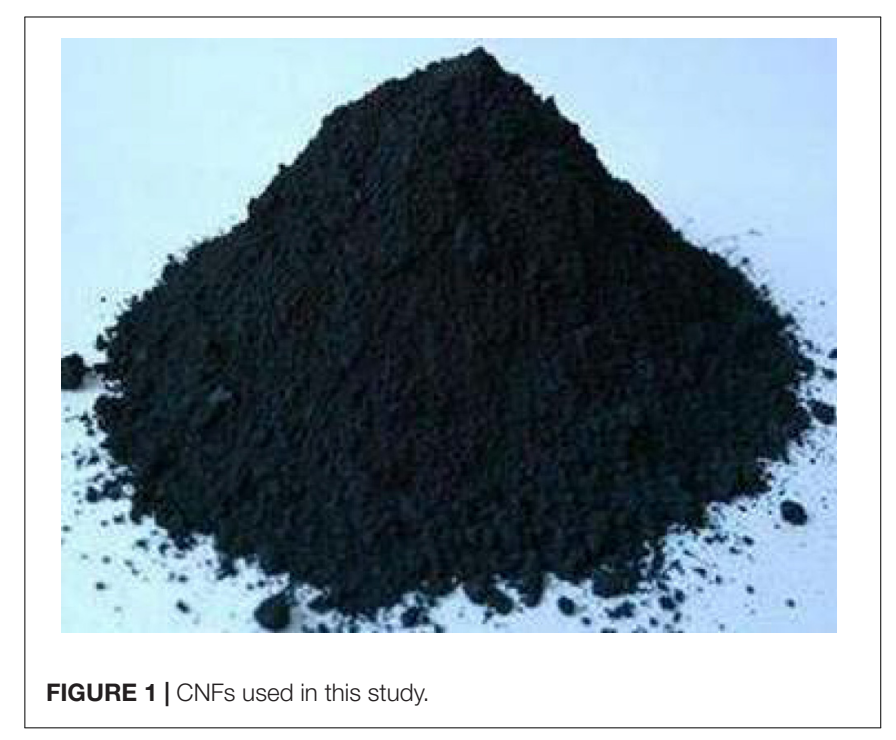


TABLE 2 | Properties of carbon nanofibers (CNFs).

\begin{tabular}{lc}
\hline Commercial name & XFM60 \\
\hline Length $(\mu \mathrm{m})$ & $5-50$ \\
Diameter $(\mathrm{nm})$ & $200-600$ \\
Surface area $\left(\mathrm{m}^{2} / \mathrm{g}\right)$ & $>18$ \\
Purity $(\%)$ & $>70$ \\
Density $\left(\mathrm{g} / \mathrm{cm}^{3}\right)$ & 2.1 \\
\hline
\end{tabular}

\section{Dispersion of CNFs}

Emulsified asphalt consists of water and asphalt, so it is feasible to disperse CNFs in water and to then produce modified emulsified asphalt. The surfactant provided by BASF Chemicals Co., Ltd. was used in this study to improve the dispersion of CNFs and the stability of the suspension. VCX800 purchased from Sonics \& Materials Co., Ltd. performed ultrasonication with a probe of a diameter of $25 \mathrm{~mm}$. Ultrasonication caused a cavity (cavitation effect) and provided energy through a cavity burst to overcome the Van der Waals forces between nanofibers and disrupted CNFs aggregation. Surfactant attached on the surface of individual CNF enhanced the isolation. This process is exhibited in Figure 2. After ultrasonication, CNF aggregation was dispersed into individual CNF surrounded by surfactant molecules.

To obtain the optimum dispersion, ultrasonication energy density (KJ/L) and the amount of surfactant are significant factors (5), which should be determined in advance. In this study, the ultrasonic instrument was input energy with a constant power of $70 \mathrm{~W}$. The energy density varied from $3000 \mathrm{KJ} / \mathrm{L}$ to $7000 \mathrm{KJ} / \mathrm{L}$, and the weight ratio of CNFs to surfactant varied from 1:3 to 1:5.

\section{UV-vis Spectra}

Individual CNT is active in the UV-vis spectra and exhibits characteristic bands corresponding to additional absorption due to van Hove singularities (Saito et al., 1992). Some researchers have obtained a strong peak of UV-vis spectra at the wavelength of approximately $250 \mathrm{~nm}$ (Chen et al., 1998; Grossiord et al., 2005; Yu et al., 2007; Cui et al., 2017). There is a certain similarity in the microstructure between $\mathrm{CNF}$ and CNT, so the UV-vis spectra can also be used to evaluate the dispersion of CNFs. The relationship between absorbance and solution concentration can be determined by Lambert-Beer law as follows (Formula 1 ), where $A$ is the absorbance; $T$ is the transmissivity; $K$ is the molar absorptivity; $\mathrm{b}$ is the thickness of the absorption layer $(\mathrm{cm})$; $c$ is the concentration of light-absorbing substances $(\mathrm{mol} / \mathrm{L})$. A higher peak value at a particular wavelength indicates a higher concentration of individual $\mathrm{CNF}$ in suspension, presenting a better dispersion state.

$$
A=\lg \left(\frac{1}{T}\right)=K b c
$$

There is a positive correlation between absorbance and solute concentration only when absorbance ranges from 0.2 to 0.8 , according to the Lambert-Beer law. The suspension was therefore diluted by 50 times its volume before measuring to control the absorbance (Figure 3).

UV-vis spectra of all suspension with different energy density and surfactant content were performed with a sweep of wavelength from 200 to $500 \mathrm{~nm}$. The results are demonstrated in Figure 4. Absorbance all appears within the expected range $(0.2-0.8)$, so the results are valid.

There is an additional absorption peak for each group at a specific wavelength of $246 \mathrm{~nm}$. The highest peak in Figure 4 indicates that the optimal dispersion method is to disperse CNFs using ultrasonication at an energy density of $5000 \mathrm{KJ} / \mathrm{L}$, accompanied by the addition of surfactant at a weight ratio of $1: 5$ to CNFs. It is noticeable that ultrasonication energy

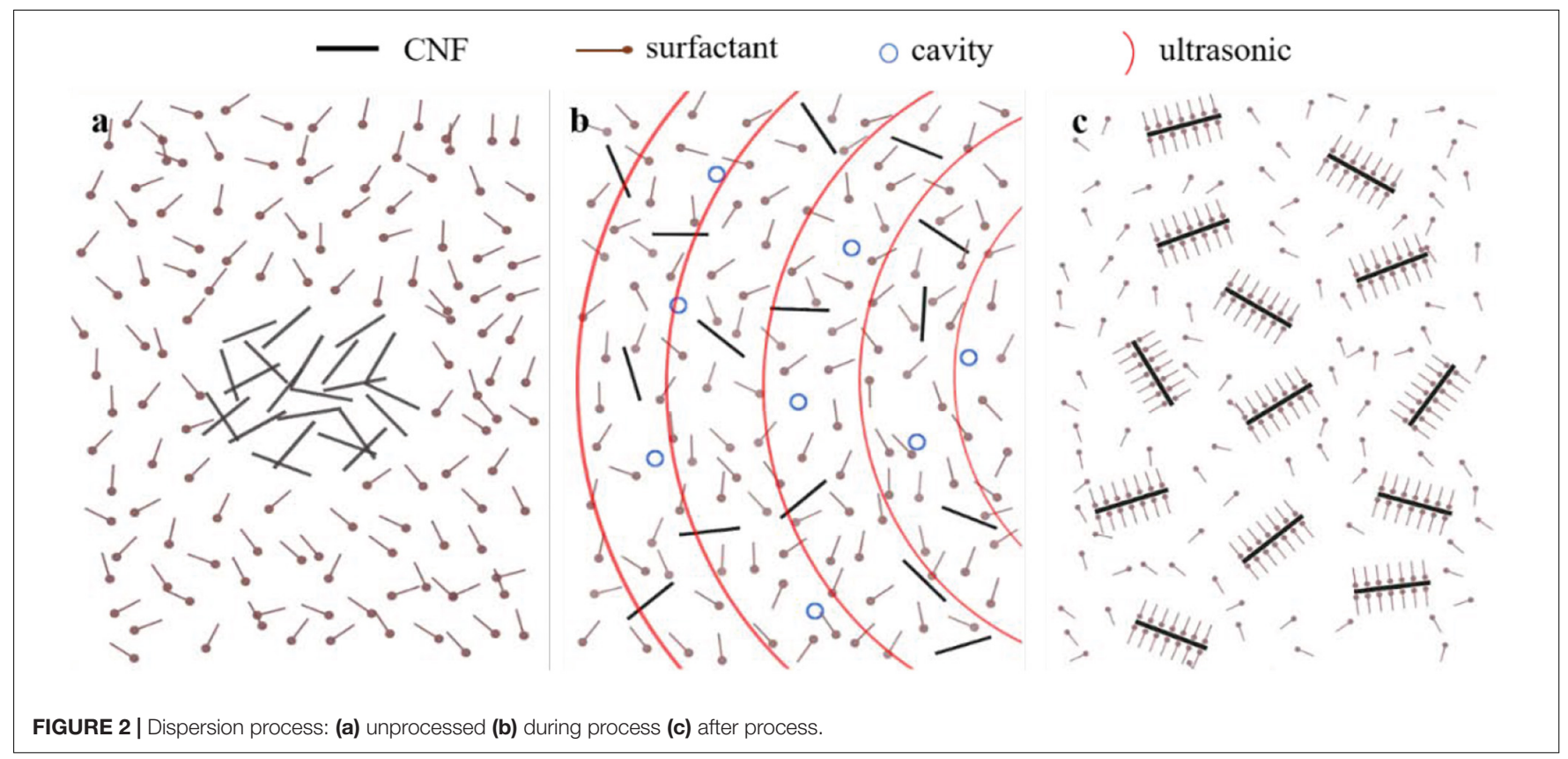




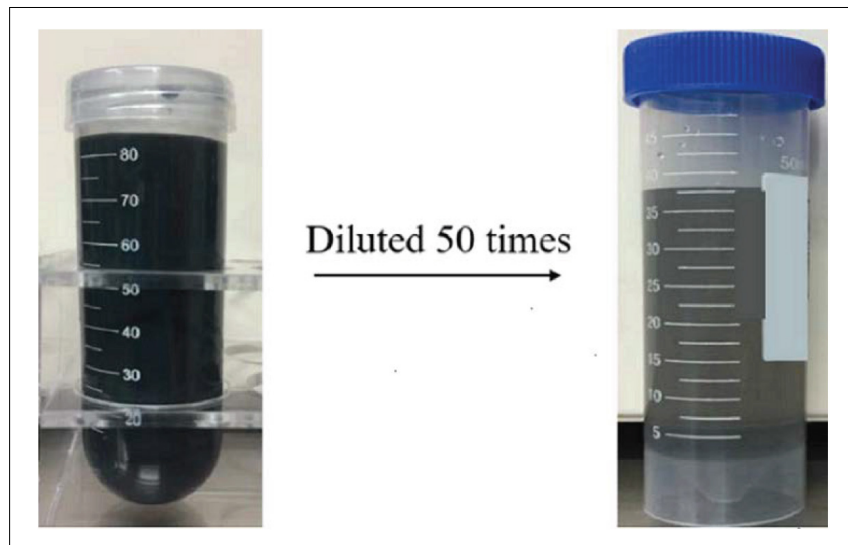

FIGURE 3 | Dilution of suspension for UV-vis spectra.

density and surfactant both impact disaggregation significantly. With the same surfactant content, the peak value of absorbance increases with the increase of energy density from 3000 to $5000 \mathrm{KJ} / \mathrm{L}$ and then decreases at a higher energy density. Similarly, under a constant energy density, more surfactant (weight ratio of CNFs to surfactant varies from 1:3 to 1:5) first contributes to a higher peak, then the absorbance decreases at the ratio of $1: 6$.

\section{Preparation of Emulsion Containing CNFs and Emulsification}

Colloidal mill MD-1 from Jiaxing Mide Machinery Co., Ltd. was utilized. In this study, the mass ratio of asphalt to emulsion (water and emulsifier) was 65:35. The emulsifier was SBT-50, provided by Westvaco Corporation. In this research, the emulsifier accounted for $3.9 \%$ of the mass of emulsified asphalt.

Carbon nanofibers content was determined by weight ratio to asphalt $(0.1,0.3,0.5$, and $1.0 \mathrm{wt} \%)$. First, CNFs were dispersed according to the optimal method above. The emulsifier was then dissolved into the suspension to obtain an emulsion. Hydrochloric acid was added to adjust $\mathrm{pH}$ value $(\mathrm{pH} \approx 2)$. Before production, the mill was heated, then materials were added to the colloid mill in this order: emulsion at $70^{\circ} \mathrm{C}$ was added and circulated for about half a minute, then hot asphalt at $135-145^{\circ} \mathrm{C}$ was added with a constant speed to ensure uniform mix. For example, assuming the mass of emulsified asphalt is $M$, and the CNFs content is $0.1 \mathrm{wt} \%$, the whole process is demonstrated in Figure 5.

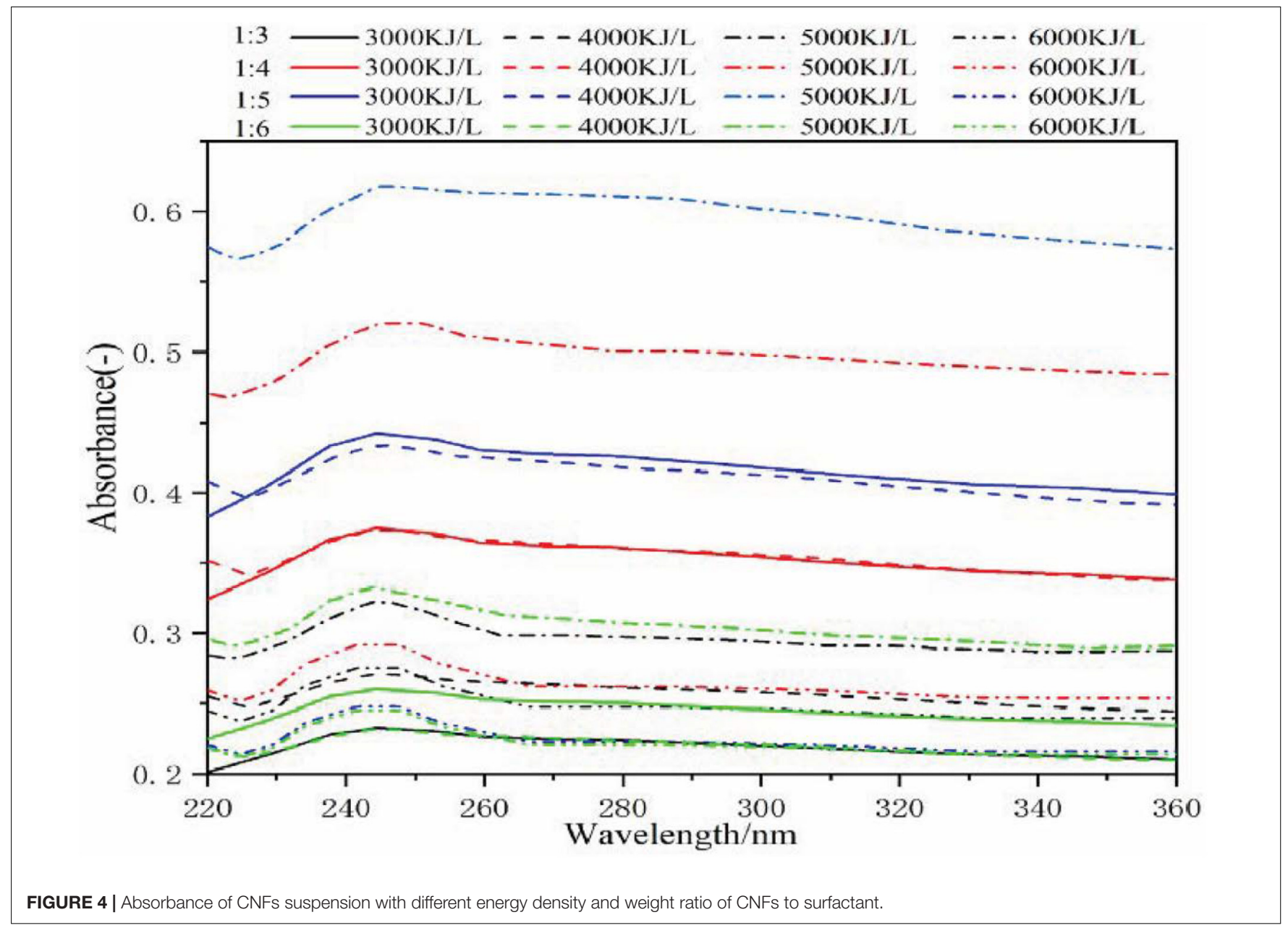




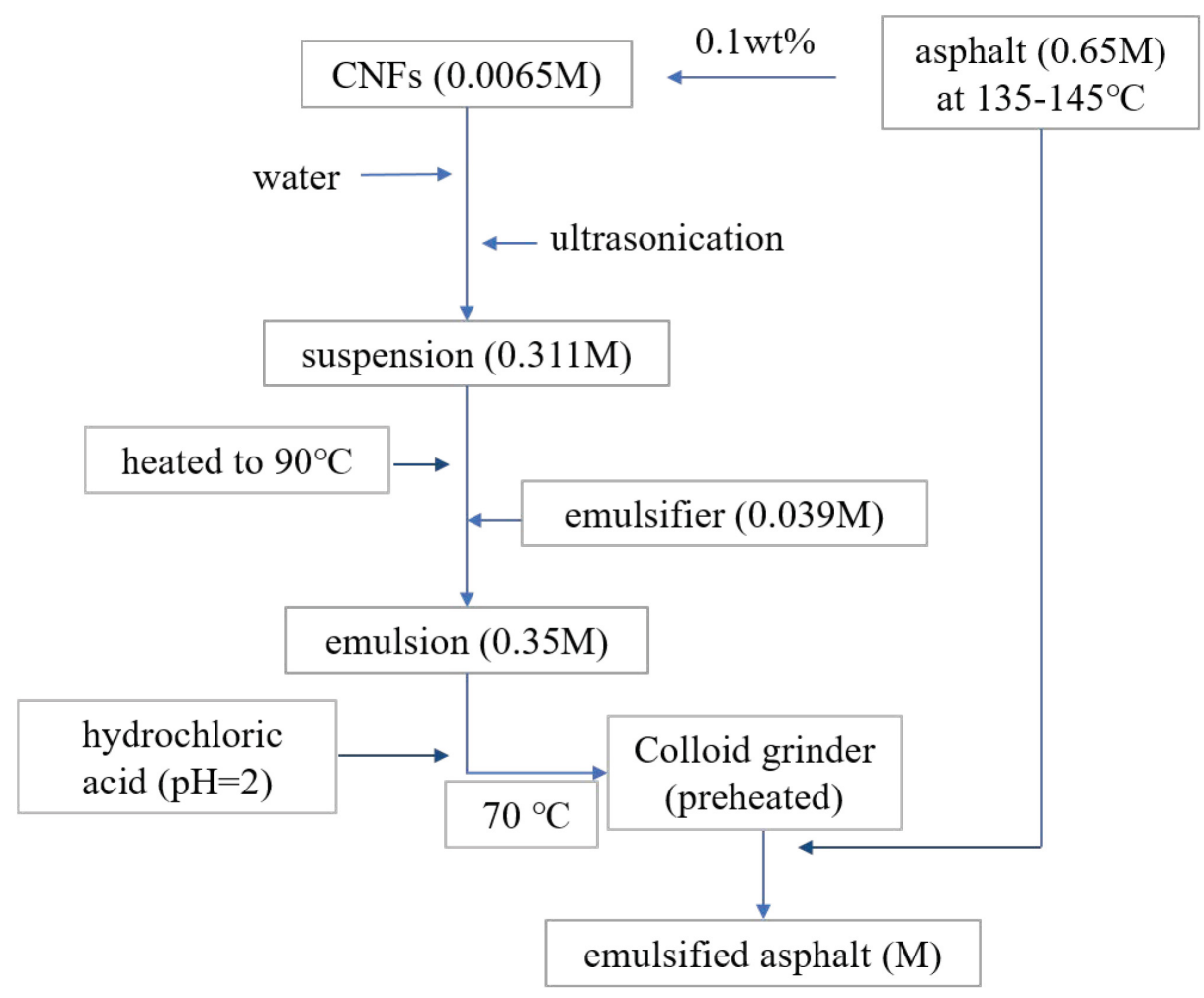

FIGURE 5 | Proportion of material and preparation for CNFs-emulsified asphalt.

TABLE 3 | Experimental group setting (0.1 wt\% CNFs for example).

ID CNFs content (wt\%) $\mathrm{NH}_{4} \mathrm{Cl}$ content (wt\%) SBR content (wt\%)

\begin{tabular}{lccc}
\hline Control & - & - & - \\
$0.1 \mathrm{C}$ & 0.1 & - & - \\
$0.1 \mathrm{C} 1 \mathrm{~N}$ & 0.1 & 1.0 & - \\
$0.1 \mathrm{C} 3 \mathrm{~N}$ & 0.1 & 3.0 & - \\
$0.1 \mathrm{C} 1 \mathrm{~N} 1 \mathrm{~S}$ & 0.1 & 1.0 & 1.0 \\
$0.1 \mathrm{C} 3 \mathrm{~N} 1 \mathrm{~S}$ & 0.1 & 3.0 & 1.0 \\
\hline
\end{tabular}

After production, ammonium chloride $\left(\mathrm{NH}_{4} \mathrm{Cl}\right)$ was added as a stabilizer. $\mathrm{NH}_{4} \mathrm{Cl}$ content varied as 0,1 , and $3 \mathrm{wt} \%$ (weight ratio to asphalt). $1 \mathrm{wt} \%$ SBR latex (weight ratio to emulsified asphalt) was added as a modifier. Table 3 shows the ID of groups with $0.1 \mathrm{wt} \%$ CNFs. The ID of groups with $0.3,0.5$, and $1.0 \mathrm{wt} \%$ CNFs are similar.

\section{EXPERIMENTS}

\section{Storage Stability}

Storage stability (1 day) at room temperature was investigated to estimate the feasibility of this preparation method. Emulsified asphalt was settled in the storage stability tube for 1 day, then the asphalt content of the $50 \mathrm{ml}$ sample from the top and the $50 \mathrm{ml}$ sample from the bottom were calculated, respectively. Their difference presents storage stability. In most situations, the emulsified asphalt is used immediately after production, so the stability of 1 day is enough to prove engineering suitability.

\section{Basic Properties of the Modified Emulsified Asphalt}

In this study, to investigate the influence of CNFs and SBR, traditional experiments were performed. The emulsified asphalt was heated to remove moisture primarily. In this process, the temperature slowly increased and was below $180^{\circ} \mathrm{C}$ to avoid asphalt aging. Then the penetration $\left(25^{\circ} \mathrm{C}\right)$, softening point, rotational viscosity $\left(135^{\circ} \mathrm{C}\right)$, and ductility $\left(5^{\circ} \mathrm{C}\right)$ were tested according to experiment specifications. Each experiment was performed three times, and the average was calculated as the final result.

\section{Gel Permeation Chromatography (GPC) Test}

Emulsified asphalt consists of components with various molecular weights, that significantly influence the properties of asphalt. In this study, the GPC test was performed to analyze the molecular weight distribution and to investigate the impact on properties. Tetrahydrofuran (THF) was selected as the solvent to dissolve the $20 \mathrm{mg}$ emulsified asphalt sample. A combination of three columns was used for separating components with various molecular weights. The solution passed through the columns at a flow rate of $1 \mathrm{~mL} / \mathrm{min}$. 


\section{RESULTS AND DISCUSSION}

\section{Storage Stability and Properties}

Experiment results of modified emulsified asphalt with $0.1 \mathrm{wt} \%$ CNFs are exhibited in Table 4.

Negative influence on stability is introduced by CNFs: the sample of $0.1 \mathrm{C}$ presents unqualified stability that is much more than the specification requirements $(<1 \%)$. However, $\mathrm{NH}_{4} \mathrm{Cl}$ significantly improves storage stability. After adding the stabilizer, the CNFs modified emulsified asphalt exhibits excellent stability (less than $1 \%$ ). The ability of group $0.1 \mathrm{C} 1 \mathrm{~N} 1 \mathrm{~S}$ is almost the same as group $0.1 \mathrm{C} 3 \mathrm{~N} 1 \mathrm{~S}$, which indicates that the $1.0 \mathrm{wt} \%$

TABLE 4 | Properties and storage stability of modified emulsified asphalt (0.1 wt $\%$ CNFs).

\begin{tabular}{lccccc}
\hline ID & \multicolumn{3}{c}{ Properties } & \multicolumn{2}{c}{$\begin{array}{c}\text { Storage } \\
\text { stability (\%) }\end{array}$} \\
\cline { 2 - 5 } & $\begin{array}{c}\text { Penetration/ } \\
\text { 0.1mm }\end{array}$ & $\begin{array}{c}\text { Softening } \\
\text { point/ }{ }^{\circ} \mathbf{C}\end{array}$ & $\begin{array}{c}\text { Rotational } \\
\text { Viscosity/ } \\
\text { Pa.s }\end{array}$ & $\begin{array}{c}\text { Ductility/ } \\
\text { cm }\end{array}$ & \\
\hline Control & 65 & 47.5 & 0.48 & 5.0 & 0.5 \\
0.1C & 57 & 50.0 & 0.51 & - & 3.2 \\
0.1C1N & 56 & 50.5 & 0.50 & - & 0.6 \\
0.1C3N & 57 & 50.0 & 0.52 & - & 0.5 \\
0.1C1N1S & 52 & 52 & 0.55 & 9.5 & 0.6 \\
0.1C3N1S & 51 & 51.5 & 0.55 & 9.9 & 0.5
\end{tabular}

stabilizer is economical. It can be thus be concluded that SBR seldomly impacts stability.

Compared to the control group, the addition of CNF improves the high-temperature properties of the residue by an increase in the softening point and rotational viscosity and a decrease in penetration. Nevertheless, on the other hand, CNFs also worsen performance under low temperatures. There is no ductility value for groups $0.1 \mathrm{C}, 0.1 \mathrm{C} 1 \mathrm{~N}$, and $0.1 \mathrm{C} 3 \mathrm{~N}$ because specimens fractured immediately under tension at $5^{\circ} \mathrm{C}$. This undesirable impact can be changed by SBR; samples with SBR show significantly higher ductility, which presents better lowtemperature performance. Further, SBR also slightly improves high-temperature properties.

\section{Effect of CNFs Content}

To investigate the effect of CNFs content on the properties of the residue, samples with $0.3,0.5$, and $1.0 \mathrm{wt} \% \mathrm{CNF}$ underwent the same experiments. The results are shown in Figure 6.

It can be seen from Figure 6 that with the increase of CNFs percentages from 0 to $0.5 \mathrm{wt} \%$, the penetration of residual asphalt decreased remarkably, while the softening point and rotational viscosity increased, which indicates an improvement in temperature performance. However, a further increase of CNFs percentages (to 1.0wt\%) induces a higher penetration value, lower softening point, and lower rotational viscosity than those of $0.5 \mathrm{wt} \%$. Compared to the control group, the residue asphalt with $0.5 \mathrm{wt} \% \mathrm{CNF}$ exhibits the best hightemperature performance, with penetration decreasing by $22.4 \%$,

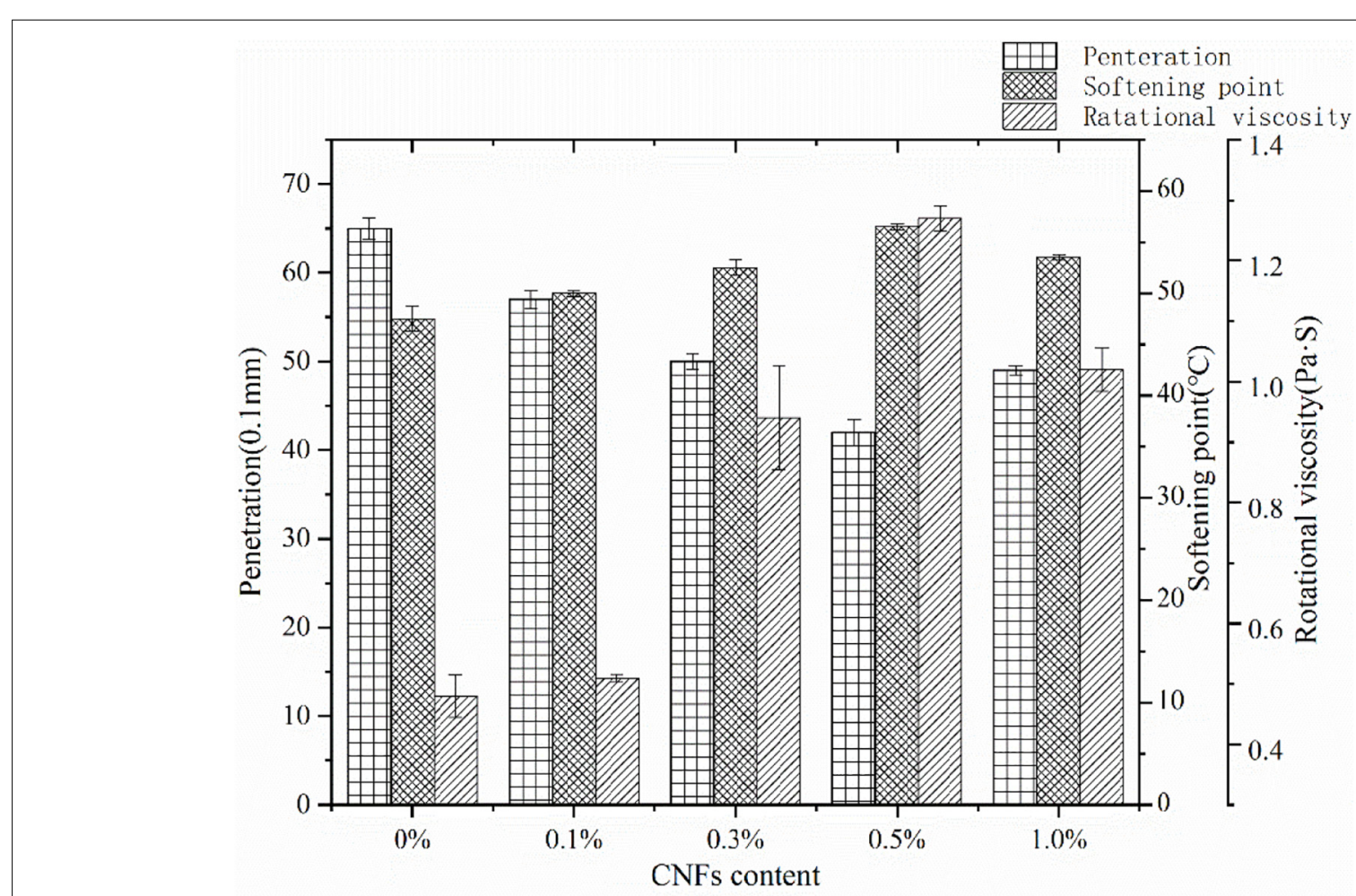

FIGURE 6 | Penetration, softening point and rotational viscosity with various CNFs percentages. 


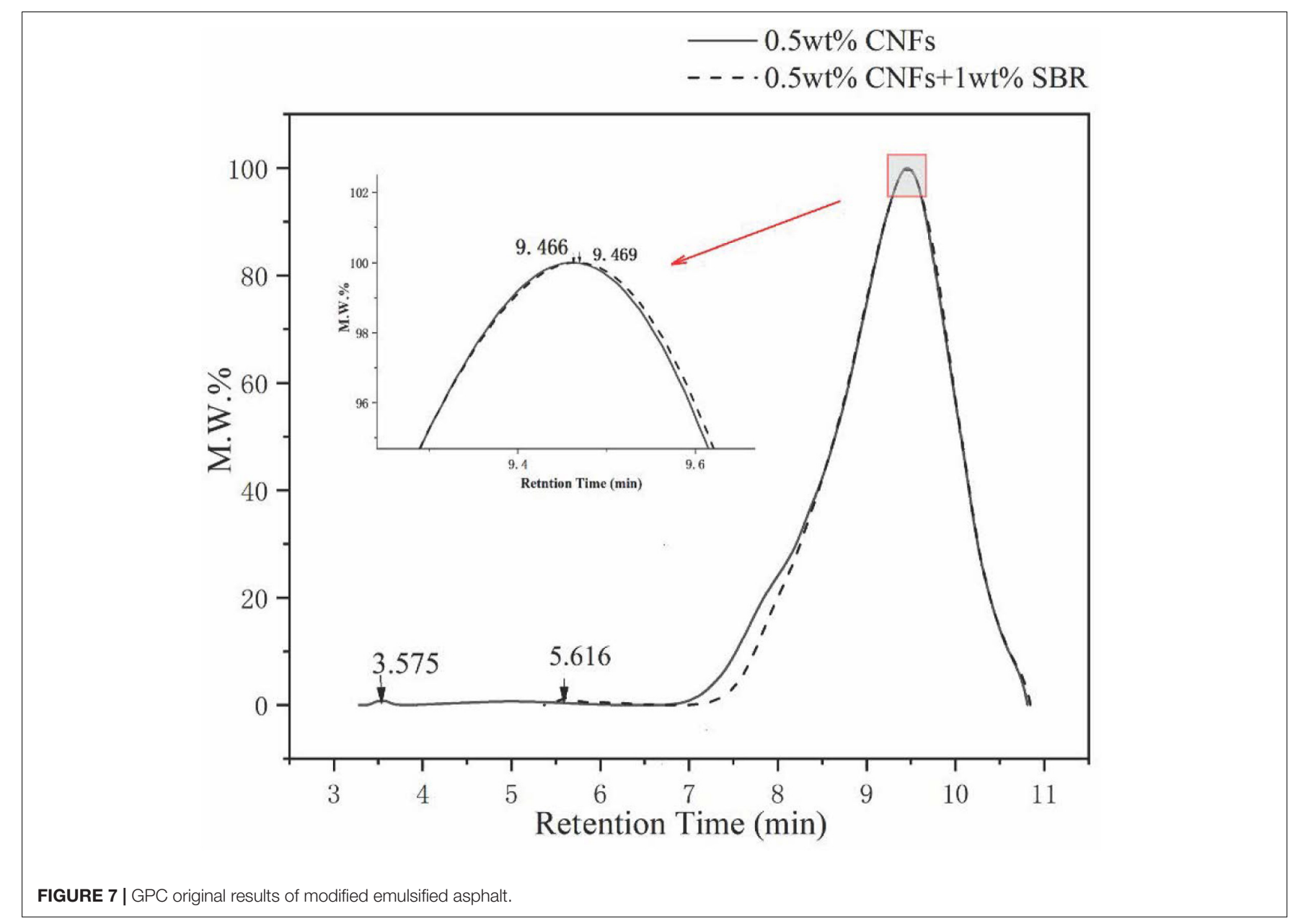

the softening point increasing by $18.9 \%$, and the rotational viscosity increasing by $164.6 \%$.

This phenomenon may be explained by the network of CNFs. Individual CNF interconnects to form a micro-network to improve high-temperature properties. More CNFs facilitate and strengthen the network structure, which stiffens the asphalt and results in better high-temperature performance. However, excessive CNFs may interfere with network formation, and the high-temperature properties worsen to some extent.

\section{GPC Results and the Effect of SBR}

Gel permeation chromatography results of the emulsified asphalt with $0.5 \mathrm{wt} \% \mathrm{CNF}$ were selected to analyze the particle size distribution and the effect of SBR. Figure 7 shows the initial results of GPC, and relevant data are presented in Table 5.

In the GPC test, smaller molecules stay in columns for longer, so the peak appears later. Figure 7 shows that before adding SBR, two peaks appear at the time of 3.575 and $9.466 \mathrm{~min}$, respectively. The addition of SBR causes two peaks to shift to the right, appearing at 5.616 and $9.469 \mathrm{~min}$, which indicates the proportion of smaller molecule increases.

Table 5 exhibits three primary data from GPC: $\mathrm{Mn}$ and $\mathrm{Mw}$ are average molecular weight in terms of number and
TABLE 5 | GPC data of samples with and without SBR.

\begin{tabular}{|c|c|c|}
\hline Data & $0.5 \mathrm{wt} \% \mathrm{CNF}$ & 0.5 wt $\%$ CNFs + 1 wt $\%$ SBR \\
\hline $\begin{array}{l}\text { Number Average Molecular } \\
\text { Weight (Mn) }\end{array}$ & 730 & 698 \\
\hline $\begin{array}{l}\text { Weight Average Molecular } \\
\text { Weight (Mw) }\end{array}$ & 15469 & 2833 \\
\hline $\mathrm{Mw} / \mathrm{Mn}$ & 21.18 & 4.06 \\
\hline
\end{tabular}

weight statistics, respectively, and their ratio $\mathrm{Mw} / \mathrm{Mn}$ presents the distribution width of molecules. The addition of SBR reduces $\mathrm{Mn}$ and $\mathrm{Mw}$ significantly, which means an increase in the proportion of small molecules. Moreover, the Mw/Mn value of the sample with SBR is far less than that without SBR, meaning a more concentrated distribution. It can be concluded that after adding SBR to the emulsified asphalt, more molecules are small molecules that distribute in a smaller range.

This conclusion is consistent with the results of ductility and storage stability. More small and flexible molecules enhance the elasticity of the residue asphalt, so the ductility under low temperature increases. Since smaller molecules settle more slowly, the stability is thus improved. On the other hand, even though SBR enhances the performance at a 
low temperature, it seldomly influences the high temperature properties like penetration and the softening point, because the high temperature performance strongly depends on the network of CNFs but the SBR fail to interfere with the network.

\section{CONCLUSION}

A method to produce CNFs modified emulsified asphalt with $\mathrm{NH}_{4} \mathrm{Cl}$ and SBR was proposed based on ultrasonication. The performance of CNFs modified emulsified asphalt was then evaluated. A GPC test was performed to investigate the effect of SBR on molecule distribution. The following conclusions were obtained:

(1) A combination of ultrasonication and surfactant is effective to disperse CNFs. To achieve uniform dispersion, the optimum weight ratio of surfactant to CNFs is 1:5, and the optimum energy density is $5000 \mathrm{KJ} / \mathrm{L}$.

(2) A method to produce CNF modified emulsified asphalt was proposed by dispersing CNFs in water with surfactant and ultrasonication in advance. The emulsifier was then dissolved into the suspension. Hot asphalt and emulsion were mixed in a colloidal mill to produce modified emulsified asphalt.

(3) Storage stability of CNF modified emulsified asphalt cannot meet the requirements, but the addition of $\mathrm{NH}_{4} \mathrm{Cl}$ improves storage stability effectively, and SBR will not influence the stability.

(4) The addition of CNFs increases the high-temperature performance and decreases the low-temperature properties

\section{REFERENCES}

Chen, J., Hamon, M. A., Hu, H., Chen, Y., Rao, A. M., Eklund, P. C., et al. (1998). Solution Properties of Single-Walled Carbon Nanotubes. Science 282:95. doi: $10.1126 /$ science.282.5386.95

Cui, H. Z., Yan, X. T., Monasterio, M., and Xing, F. (2017). Effects of Various Surfactants on the Dispersion of MWCNTs-OH in Aqueous Solution. Nanomaterials 7:14. doi: 10.3390/nano7090262

Galao, O., Baeza, F. J., Zornoza, E., and Garcés, P. (2014). Strain and damage sensing properties on multifunctional cement composites with CNF admixture. Cement Concrete Composites 46, 90-98. doi: 10.1016/j.cemconcomp.2013. 11.009

Gdoutos, E. E., Konsta-Gdoutos, M. S., Danoglidis, P. A., and Shah, S. P. (2016). Advanced cement based nanocomposites reinforced with MWCNTs and CNFs. Front. Struct. Civil Eng. 10:142-149. doi: 10.1007/s11709-016-0342-1

Goh, S. W., Akin, M., You, Z. P., and Shi, X. M. (2011). Effect of deicing solutions on the tensile strength of micro- or nano-modified asphalt mixture. Construct. Build. Mater. 25, 195-200. doi: 10.1016/j.conbuildmat.2010.06.038

Grossiord, N., Regev, O., Loos, J., Meuldijk, J., and Koning, C. E. (2005). Timedependent study of the exfoliation process of carbon nanotubes in aqueous dispersions by using UV-visible spectroscopy. Anal. Chem. 77, 5135-5139. doi: 10.1021/ac050358j

Khattak, M. J., Khattab, A., and Rizvi, H. R. (2013a). Characterization of carbon nano-fiber modified hot mix asphalt mixtures. Construct. Build. Mater. 40, 738-745. doi: 10.1016/j.conbuildmat.2012.11.034

Khattak, M. J., Khattab, A., Zhang, P. F., Rizvi, H. R., and Pesacreta, T. (2013b). Microstructure and fracture morphology of carbon nano-fiber modified asphalt and hot mix asphalt mixtures. Mater. Struc. 46, 2045-2057. doi: 10.1617/ s11527-013-0035-33

Khattak, M. J., Khattab, A., Rizvi, H. R., and Zhang, P. F. (2012). The impact of carbon nano-fiber modification on asphalt binder rheology. of the residue. Residue with a CNFs percentage of 0.5 wt $\%$ exhibit the best high temperature performance (penetration decreased by $22.4 \%$, softening point increased by $18.9 \%$, and rotational viscosity increased by $164.6 \%$ ).

(5) GPC results indicate that SBR improves low-temperature ductility of residue asphalt significantly by increasing the proportion of small molecules.

\section{DATA AVAILABILITY STATEMENT}

All datasets generated for this study are included in the article/supplementary material.

\section{AUTHOR CONTRIBUTIONS}

JF, FL, and XZ conceived the presented study idea. XL and YA performed the experiments and collected the data. XL wrote the manuscript with support from FL. All authors discussed the results and contributed to the final manuscript.

\section{FUNDING}

This study was supported by the National Key R\&D Program of China (2018YFB1600100), the National Natural Science Foundation of China (Nos. 51622805 and 51978029), and the Shandong Provincial Department of Transportation (No. 2018BZ4).

Construct. Build. Mater. 30, 257-264. doi: 10.1016/j.conbuildmat.2011. 12.022

Konsta-Gdoutos, M. S., and Aza, C. A. (2014). Self sensing carbon nanotube (CNT) and nanofiber (CNF) cementitious composites for real time damage assessment in smart structures. Cement Concrete Compos. 53, 162-169. doi: 10.1016/j.cemconcomp.2014.07.003

Konsta-Gdoutos, M. S., Batis, G., Danoglidis, P. A., Zacharopoulou, A. K., Zacharopoulou, E. K., Falara, M. G., et al. (2017). Effect of CNT and CNF loading and count on the corrosion resistance, conductivity and mechanical properties of nanomodified OPC mortars. Construct. Build. Mater. 147, 48-57. doi: 10.1016/j.conbuildmat.2017.04.112

Lawrence, J. G., Berhan, L. M., and Nadarajah, A. (2008). Elastic properties and morphology of individual carbon nanofibers. Acs Nano 2, 1230-1236. doi: 10. 1021/nn7004427

Metaxa, Z. S., Konsta-Gdoutos, M. S., and Shah, S. P. (2013). Carbon nanofiber cementitious composites: effect of debulking procedure on dispersion and, reinforcing efficiency. Cement Concrete Compos. 36, 25-32. doi: 10.1016/j. cemconcomp.2012.10.009

Mordkovich, V. Z. (2003). Carbon nanofibers: a new ultrahigh-strength material for chemical technology. Theor. Found. Chem. Eng. 37, 429-438. doi: 10.1023/a: 1026082323244

O'Connell, M. J., Bachilo, S. M., Huffman, C. B., Moore, V. C., Strano, M. S., Haroz, E. H., et al. (2002). Band gap fluorescence from individual singlewalled carbon nanotubes. Science 297, 593-596. doi: 10.1126/science.107 2631

Ouyang, J., Yang, W., Chen, J., and Han, B. (2020). Effect of Superplasticizer and Wetting Agent on Pavement Properties of Cold Recycled Mixture with Bitumen Emulsion and Cement*. 32, 04020136. doi: 10.1061/(ASCE)MT.19435533.0003194

Ouyang, J., Zhao, J., and Tan, Y. (2018). Modeling Mechanical Properties of Cement Asphalt Emulsion Mortar with Different Asphalt to Cement Ratios 
and Temperatures*. 30, 04018263. doi: 10.1061/(ASCE)MT.1943-5533.000 2480

Pacheco-Torgal, F., and Jalali, S. (2011). Nanotechnology: advantages and drawbacks in the field of construction and building materials. Construct. Build. Mater. 25, 582-590. doi: 10.1016/j.conbuildmat.2010.07.009

Saito, R., Fujita, M., Dresselhaus, G., and Dresselhaus, M. S. (1992). Electronic structure of chiral graphene tubules. Appl. Phys. Lett. 60, 2204-2206. doi: 10. $1063 / 1.107080$

Strano, M. S., Moore, V. C., Miller, M. K., Allen, M. J., Haroz, E. H., Kittrell, C., et al. (2003). The role of surfactant adsorption during ultrasonication in the dispersion of single-walled carbon nanotubes. J. Nanosci. Nanotechnol. 3, 81-86. doi: 10.1166/jnn.2003.194

Yazdanbakhsh, A., Grasley, Z., Tyson, B., and Al-Rub, R. K. A. (2009). Carbon nano filaments in cementitious materials: some issues on dispersion and interfacial bond*. Spec. Publ. 267, 21-34. doi: 10.14359/51663280

Yazdanbakhsh, A., Grasley, Z., Tyson, B., and Abu Al-Rub, R. K. (2010). Distribution of carbon nanofibers and nanotubes in cementitious composites. Trans. Res. Rec. 89-95. doi: 10.3141/2142-13
Yu, J. R., Grossiord, N., Koning, C. E., and Loos, J. (2007). Controlling the dispersion of multi-wall carbon nanotubes in aqueous surfactant solution. Carbon 45, 618-623. doi: 10.1016/j.carbon.2006.10.010

Zhu, X. Y., Gao, Y., Dai, Z. W., Corr, D. J., and Shah, S. P. (2018). Effect of interfacial transition zone on the Young's modulus of carbon nanofiber reinforced cement concrete. Cement Concrete Res. 107, 49-63. doi: 10.1016/j.cemconres.2018.02.014

Conflict of Interest: The authors declare that the research was conducted in the absence of any commercial or financial relationships that could be construed as a potential conflict of interest.

Copyright (C) $2020 \mathrm{Liu}$, An, Feng, Zhu and Li. This is an open-access article distributed under the terms of the Creative Commons Attribution License (CC BY). The use, distribution or reproduction in other forums is permitted, provided the original author(s) and the copyright owner(s) are credited and that the original publication in this journal is cited, in accordance with accepted academic practice. No use, distribution or reproduction is permitted which does not comply with these terms. 